\title{
Effects of High Temperature and Drought on a Hybrid Bluegrass Compared with Kentucky Bluegrass and Tall Fescue
}

\author{
Kemin Su, Dale J. Bremer*, Steven J. Keeley, and Jack D. Fry
}

Accepted for publication in Crop Science, September 2007.

Dep. of Horticulture, Forestry \& Recreation Resources, 2021 Throckmorton Hall, Kansas State Univ., Manhattan, KS 66506. Contribution no. 07-185-J from the Kansas Agric. Exp. Station. *Corresponding author (bremer@ksu.edu).

\footnotetext{
Abbreviations: DOT, days of treatment; EL, electrolyte leakage; ET, evapotranspiration; HBG, a hybrid between Kentucky and Texas bluegrass; KBG, Kentucky bluegrass; LAI, leaf area index; Pg, gross photosynthesis; TF, tall fescue.
} 


\begin{abstract}
High temperature and drought stresses may reduce quality in cool-season turfgrasses during summer months in the transition zone. This growth chamber study was conducted to evaluate effects of high temperature and drought on physiology and growth of 'Apollo' Kentucky bluegrass (Poa pratensis L.) (KBG), 'Dynasty' tall fescue (Festuca arundincea Schreb.) (TF), and 'Thermal Blue', a hybrid (HBG) between KBG and Texas bluegrass (Poa arachnifera Torr.). Turfgrasses were exposed for 48 days to supra-optimal (high temperature; 35/25 ${ }^{\circ} \mathrm{C}, 14-\mathrm{h}$ day/10-h night) and optimal (control; 22/15 $\mathrm{C}, 14$-h day/10-h night) temperatures under well-watered (100\% evapotranspiration [ET] replacement) and deficit (60\% ET replacement) irrigation. Heat resistance was greater in $\mathrm{HBG}$, which had greater visual quality, gross photosynthesis $(\mathrm{Pg})$, dry matter production, and lower electrolyte leakage and soil-surface temperatures than KBG and TF under high temperature. Cumulative Pg during the study was $16 \%$ and $24 \%$ greater in $\mathrm{HBG}$ than in $\mathrm{KBG}$ and $\mathrm{TF}$, respectively. Green leaf area index (LAI) in HBG was not affected by high temperature, but LAI was reduced by $29 \%$ in KBG and $38 \%$ in TF. Differences in drought resistance were negligible among species. The combination of high temperature and drought caused rapid declines in visual quality and dry matter production, but HBG generally performed better. Results indicated greater heat resistance, but not drought resistance, in $\mathrm{HBG}$ than in $\mathrm{KBG}$ or $\mathrm{TF}$.
\end{abstract}


High temperature and drought stresses are significant problems in cool-season turfgrasses during summer months in the U.S. transition zone, which covers 480 to $1120 \mathrm{~km}$ north to south between the northern regions where cool-season grasses are adapted and the southern regions where warm-season grasses are adapted (Dunn and Diesburg, 2004). High temperature and drought stresses often occur simultaneously during summer months and may limit growth and cause a severe decline in the visual quality of cool-season turfgrasses (Perdomo et al., 1996; Bonos and Murphy, 1999; Jiang and Huang, 2000; Wang and Huang, 2004). Recent increases in competition for water have resulted in restrictions in water use for irrigation of turfgrasses (EIFG, 2004), which further exacerbates the problem of drought stress in cool-season turfgrasses. Predictions of higher temperatures from global warming also suggest that heat stress in cool-season turfgrasses may become more common in some regions, including the transition zone (National Assessment Synthesis Team, 2000).

Hybrid bluegrasses (HBG), which are genetic crosses between native Texas bluegrass and $\mathrm{KBG}$, may have greater heat and drought resistance than other cool-season grasses. Hybrid bluegrasses have similar visual qualities to KBG, which is a fine-textured, cool-season turfgrass commonly used in lawns and golf courses in the U.S. (Read et al., 1999; Turgeon, 2002). Consequently, new cultivars of HBG are being investigated as potential water-saving, heatresistant alternatives to current cool-season turfgrasses.

Abraham et al. (2004) evaluated, in a growth chamber study, the drought resistance of thirty HBG and their genetic parents and concluded that their drought resistance varied significantly. Those researchers also determined that highly drought resistant hybrids could be achieved by selecting first generation hybrids with good drought resistance and backcrossing them with elite drought resistant genotypes of KBG. In field tests in Colorado, USA, 'Reveille' 
HBG used significantly less water while maintaining higher quality than 'Bensun's A-34' KBG (Suplick-Ploense and Qian, 2005). Bremer et al. (2006) reported little difference in the general performance or drought resistance among two HBG (Thermal Blue and 'Dura Blue') and a KBG (Apollo) in a field study in Kansas, USA. Dura Blue HBG and Apollo KBG were the most desirable among five cool-season turfgrasses under different nitrogen rate levels in Tennessee, USA (Teuton et al., 2005). Thermal Blue and Dura Blue HBG may be acceptable replacements for KBG in the Upper Midwest, USA because they had similar quality and earlier spring greenup than KBG (Stier et al, 2005). However, little information is available about the effects of both high temperature and drought on HBG.

The objectives of this study were to evaluate the effects of high temperature and drought stress on the growth, appearance, and physiology of HBG, KBG, and TF.

\section{Materials and Methods}

Preparation and maintenance of turfgrasses in lysimeters

Lysimeters (10 cm diam. by $60 \mathrm{~cm}$ deep) were filled with a mixture of sand and topsoil (1:1, v:v) and bulk densities inside lysimeters ranged from 1.62 to $1.70 \mathrm{~g} \mathrm{~cm}^{-3}$. Apollo $\mathrm{KBG}$ and Thermal Blue HBG were seeded at $153 \mathrm{~kg} \mathrm{ha}^{-1}$ and Dynasty TF was seeded at $395 \mathrm{~kg} \mathrm{ha}^{-1}$ in lysimeters. They were kept under a mist system after seeding for about $30 \mathrm{~d}$ in a greenhouse. The mist system was automatically turned on 4 times per day for 5 min each. After $30 \mathrm{~d}$, lysimeters were moved away from the mist system but continued to be maintained in the greenhouse. Average day/night air temperature was $22^{\circ} \mathrm{C} / 15^{\circ} \mathrm{C}$ and supplemental light was $12-\mathrm{h} /$ day. Turfgrasses were well-watered, mowed twice weekly at $6.5 \mathrm{~cm}$, and fertilized weekly at the rate 
of $15 \mathrm{~kg} \mathrm{~N} \mathrm{ha}^{-1}$ (15N-13P-12K). Totally, turfgrasses were planted and maintained in the greenhouse for about $135 \mathrm{~d}$.

Lysimeters were then transferred to growth chambers at $22^{\circ} \mathrm{C} / 15^{\circ} \mathrm{C}, 14-\mathrm{h}$ day $/ 10$-h night with photosynthetically active radiation of $580 \mu \mathrm{mol} \mathrm{m}^{-2} \mathrm{~s}^{-1}$ during the daylight period. The turfgrasses were kept well-watered in the growth chambers for $14 \mathrm{~d}$ to allow for acclimation to growth chambers before treatments. Turfgrasses were mowed and watered every $3 \mathrm{~d}$ and fertilized every $6 \mathrm{~d}$ with a solution supplying $20 \mathrm{~kg} \mathrm{~N} \mathrm{ha}^{-1}(15 \mathrm{~N}-13 \mathrm{P}-12 \mathrm{~K})$ during the treatments.

\section{Treatments and Experimental Design}

Thermal Blue HBG, Apollo KBG, and Dynasty TF were exposed to the following treatments in growth chambers: (i) supra-optimal temperature (high temperature; $35 / 25^{\circ} \mathrm{C}, 100 \%$ ET); (ii) drought $\left(22 / 15^{\circ} \mathrm{C}, 60 \% \mathrm{ET}\right)$; (iii) high temperature and drought $\left(35 / 25^{\circ} \mathrm{C}, 60 \% \mathrm{ET}\right)$; and (iv) optimal temperature (control; $22 / 15^{\circ} \mathrm{C}, 100 \% \mathrm{ET}$ ).

Six whole plots (two temperature treatments $\mathrm{x}$ three replications) and six subplots per whole plot (three species $\mathrm{x}$ two irrigation treatments), for a total of 36 subplots, were arranged in a split-plot design. Whole plots were the growth chambers, where the supra-optimal and optimal temperature treatments were applied in separate chambers in a randomized complete block design. Subplots, which were the lysimeters, were arranged in a completely randomized design within each whole plot. Because only two growth chambers were available, whole plots could not be replicated concurrently and had to be replicated sequentially in time. The first whole-plot replication was from March to May 2004, the second replication from May to July 2004, and the third from July to September 2004. To ensure that turf age was similar in each replication, turfgrasses were seeded in lysimeters 5 mo before treatments were applied. Therefore, lysimeters 
for the first, second, and third replications (blocks) were seeded in October 2003, December 2003, and January 2004, respectively.

Evapotranspiration (100\%) was measured gravimetrically with the well-watered lysimeters (Bremer, 2003). Using this method, lysimeters were irrigated, allowed to drain until free drainage ceased, sealed, and weighed. Lysimeters were then weighed after $3 \mathrm{~d}$ and the water loss was attributed to ET. Lysimeters were irrigated every $3 \mathrm{~d}$ according to their ET losses. Cumulative ET $(\mathrm{mm})$ for each treatment was determined as the sum of all ET during the study.

Turfgrass quality, photosynthesis, electrolyte leakage, and canopy temperature

Turf visual quality was rated on a scale of 1 to 9 (1=poorest quality, $6=$ minimally acceptable, and 9=highest quality) according to color, texture, density, and uniformity (Emmons, 2000). Quality ratings were recorded every $6 \mathrm{~d}$ by the same individual during the entire study.

Photosynthesis was measured every $6 \mathrm{~d}$ at about $8 \mathrm{~h}$ into the daily light cycle, with a LI6400 portable gas exchange system (LI-COR Inc., Lincoln, NE) using a custom surface chamber described by Bremer and Ham (2005). According to their Equations 5 and 6, sunlit chamber measurements determine $\mathrm{Pg}-\left(R c+R s^{\prime}\right)$ and shaded chamber measurements determine $R c+$ $R s^{\prime}$, where Pg is gross photosynthesis, Rc is canopy respiration, and Rs' is residual soil respiration in a pressurized chamber; all values are positive and units are $\mu \mathrm{mol} \mathrm{m} \mathrm{m}^{-2}$. Shaded chamber measurements were obtained by covering the chamber with a black cloth that completely blocked solar radiation from the chamber. Gross photosynthesis was calculated using equation 8 in Bremer and Ham (2005): Pg = sunlit chamber + shaded chamber. Cumulative Pg for each treatment was calculated by summing the products of mean Pg on each measurement 
day and the number of hours between samples when lights were turned on (i.e., 14 h daily period when plants were photosynthesizing).

Leaf electrolyte leakage (EL) was determined by the method of Blum and Ebercon (1981) and Marcum (1998) with modifications. Five living leaves about the same age were collected from each lysimeter at $0,3,15,27,39$, and 45 days of treatment (DOT). Each leaf was cut into two to three $2-\mathrm{cm}$ segments and rinsed 3 times with distilled deionized water. All rinsed leaf segments from each lysimeter were placed in a test tube containing $20 \mathrm{ml}$ deionized water. Test tubes were shaken on a shaker table at 120 RPM (Lab-Line Instruments Inc., Melrose Park, Illinois) for $24 \mathrm{~h}$ to dissolve electrolytes that had leaked from cells (e.g., due to membranes damaged by heat or drought stress treatments). After measuring conductivity $\left(\mathrm{C}_{1}\right)$ with a conductivity meter (Model 32, Yellow Spring Instrumental Inc., Yellow Spring, Ohio), the test tubes with leaf samples were placed in an autoclave at $140^{\circ} \mathrm{C}$ for $20 \mathrm{~min}$ to destroy all cell membranes, shaken for $24 \mathrm{~h}$ to extract all electrolytes from the cells, and then the conductivity $\left(\mathrm{C}_{2}\right)$ was measured again. The percentage of the total electrolytes that had leaked from cells during treatments was calculated as $\left(\mathrm{C}_{1} / \mathrm{C}_{2}\right) * 100$. Lower EL indicated greater resistance to stresses.

Canopy temperature was measured every $6 \mathrm{~d}$ with three infrared thermometers (model IRTP5, Apogee, Logan, UT). The infrared thermometers were positioned at $0.2 \mathrm{~m}$ above the turf canopy. Measurements were automatically logged every $5 \mathrm{sec}$ and averaged and recorded every 30 min with a micrologger (CR10x, Campbell Scientific, Logan, UT). Measurements for each lysimeter were conducted for about 1.5 to $2.5 \mathrm{~h}$.

Dry matter production, soil-surface temperature, and volumetric soil water content 
Turfgrasses were mowed every $3 \mathrm{~d}$, and all clippings were collected. Clippings were dried in a forced-air oven for $48 \mathrm{~h}$ at $70^{\circ} \mathrm{C}$ and then weighed. Cumulative dry matter production for each treatment was determined by summing the dry weights of all clippings during the $48 \mathrm{~d}$ study. Daily dry matter production was calculated as the clipping weight at each mowing divided by the number of days since the previous mowing.

Soil surface temperature was measured with soil-encapsulated thermocouples using the method of Ham and Senock (1992). To evaluate potential cumulative heat effects among treatments during the most stressful periods, heat units (degree-hours) were calculated as the sum of soil surface temperatures during the final $8 \mathrm{~h}$ of each daily light cycle. Our data indicated that this was the period of maximum soil surface temperatures, which may have had important physiological impacts on the turfgrasses (e.g., on meristematic activity in the crowns).

Volumetric soil water content $\left(\theta_{\mathrm{v}}\right)$ and temperature inside the lysimeters at 5, 25, and 45 $\mathrm{cm}$ were measured automatically using the dual-probe heat-pulse technique (Campbell et al., 1991; Tarara and Ham, 1997; Song et al., 1998). Sensors were fabricated in the laboratory as described by Basinger et al. (2003) and Bremer (2003). Measurements of $\theta_{\mathrm{v}}$ were logged twice daily at 0800 and $2000 \mathrm{CST}$ and soil temperatures were logged every $60 \mathrm{~min}$. All data acquisition and control were accomplished with a micrologger and accessories (CR10x, two AM16/32's, and one AM25T, Campbell Scientific, Logan, UT).

\section{Green leaf area index, aboveground biomass, and root mass density}

At the end of each $48 \mathrm{~d}$ replication, aboveground biomass was harvested from each lysimeter and separated into living and dead components. Green leaves were separated from green shoots and the area of the leaves was measured with an area meter (LI-3100, LI-COR, 
Lincoln, NE). All green and dead tissue was then dried in a forced-air oven for $48 \mathrm{~h}$ at $70^{\circ} \mathrm{C}$ and weighed separately. Green LAI was calculated as the ratio of the green leaf area to ground surface, and total aboveground biomass for each treatment was calculated as the sum of the dry weights of all living and dead tissue.

After aboveground biomass was harvested, lysimeters were laid horizontally and cut into three sections ( 0 to 15,15 to 35 , and 35 to $57.5 \mathrm{~cm}$ ). The soil was washed from the roots in each section and roots were dried in a forced-air oven for $48 \mathrm{~h}$ at $70^{\circ} \mathrm{C}$ and then weighed. Root mass density of each section was calculated as dry root mass divided by the volume of soil inside each respective section of lysimeter.

All data were analyzed with the mixed procedure of SAS (SAS Institute Inc., Cary, NC). Variation was partitioned into grass species, temperature treatment, and irrigation level. Interactions among species, temperature, and irrigation level were not significantly different on a given day after treatment initiation (Days of treatment). Therefore, the comparison of species under temperature and / or drought treatments was statistically analyzed. Differences between means were separated by the least significance difference (LSD) test at $\mathrm{P}=0.05$.

\section{Results and Discussion}

\section{Visual quality}

In the high temperature treatment, HBG consistently had the highest visual quality of all three species, always greater than or equal to a relative quality rating of six (Fig. 1A). Visual quality of HBG was significantly greater than TF and KBG starting on 24 and 42 DOT, respectively, and differences remained significant thereafter. Visual quality of KBG was also significantly greater than TF during the last week of the study (i.e., 42 and 48 DOT). 
Under drought stress at optimal temperatures, visual quality of all turfgrasses began to decline after about 2 wk (Fig. 1B). Although the quality of HBG was greater than TF on 6 and 12 DOT, this was consistent with the control, in which HBG was also higher than TF on those dates under well-watered conditions (Fig. 1D). As the severity of drought effects intensified, differences in quality between HBG and TF diminished. Visual quality was similar among species after 12 DOT, which indicates no differences in drought resistance among species. These results contradict Supplick-Ploense and Qian (2005), who found greater drought resistance in HBG (Reveille) because of its greater root length density and root mass. Our results also contradict Bremer et al. (2006), who reported that TF had greater drought resistance than HBG in the field. In contrast to the previous studies in which soils were deep, the development of roots in our study was probably more restricted because of limited soil volumes and soil water reservoirs inside lysimeters. Thus, our results may be more comparable to turfgrasses grown in shallow or poor soils such as is typical of home lawns, where soils are often disturbed, layered, and compacted during home construction (Hamilton and Waddington, 1999).

The combination of high temperature and drought stresses caused a more rapid decline in visual quality among species than individual treatments of high temperature or drought (Figs. 1A, 1B, and 1C). For example, visual quality of TF fell below 6 by 6 DOT, and HBG and KBG fell below 6 by 18 DOT. Nevertheless, the visual quality of HBG was consistently higher among species late in the study (i.e., after 18 DOT), albeit significantly higher only than TF.

In the control, visual quality was consistently higher in HBG and KBG than in TF although differences were not always significant; visual qualities were similar between HBG and KBG (Fig. 1D). Tall fescue had a lower visual quality than HBG and KBG in the control primarily because of its coarser texture. 
Photosynthesis

High temperature reduced cumulative Pg by $21 \%$ in $\mathrm{HBG}, 30 \%$ in $\mathrm{KBG}$, and $27 \%$ in $\mathrm{TF}$, compared with the control (Fig. 2). In the high temperature treatment, however, cumulative Pg of HBG was $16 \%$ greater than KBG and $24 \%$ greater than TF. During the study, high temperature caused a general decline in daily Pg among species although Pg was consistently higher in HBG than in TF and KBG late in the study (Fig. 3). Daily Pg was significantly higher in HBG than in TF from 24 through 42 DOT, and higher in HBG than in KBG on 42 DOT. These data indicate greater resistance to heat in $\mathrm{HBG}$ than in $\mathrm{TF}$ and $\mathrm{KBG}$.

Drought stress reduced cumulative Pg by $36 \%$ in $\mathrm{HBG}, 33 \%$ in $\mathrm{KBG}$, and $29 \%$ in $\mathrm{TF}$, compared with the control (Fig. 2). Late in the study, the deleterious effects of sustained drought on daily Pg surpassed that of well-watered turfgrasses experiencing only high temperature stress (data not shown). Cumulative Pg under drought stress was similar among species, however, indicating no differences in drought resistance among the three species as related to photosynthetic capacity.

Under combined high temperature and drought stress, cumulative Pg of HBG, KBG, and TF was reduced by $51 \%, 56 \%$, and $60 \%$, respectively, compared with the control (Fig. 2). The combination of high temperature and drought stresses reduced cumulative $\mathrm{Pg}$ more than individual treatments of high temperature or drought. This result is similar to other reports where the combined stresses of heat and drought caused photosynthesis to decline in Kentucky bluegrass (Jiang and Huang, 2000) and in tall fescue (Jiang and Huang, 2001). Wang and Huang (2004) reported that the combination of high temperature and drought stresses decreased leaf photochemical efficiency and chlorophyll content of two Kentucky bluegrass cultivars 
('Midnight' and 'Brilliant') and had a detrimental effect on the photosynthesis system for Kentucky bluegrass. Cumulative Pg in this study was greater in HBG than in TF under the combined stresses of high temperature and drought.

\section{Electrolyte leakage (EL)}

High temperature had no effect on EL in well-watered HBG, but EL increased in wellwatered KBG on 27 DOT, and remained higher than HBG thereafter (Fig. 4A). Mean EL also increased in TF on 27 DOT and remained higher than HBG thereafter, but differences were significant only on 39 DOT. Drought stress under optimal temperatures had no significant effect on EL among species, although mean EL was consistently higher in TF among species beginning on 15 DOT (Fig. 4B). The combination of high temperature and drought caused EL to increase in all species (Fig. 4C). Interestingly, EL decreased in HBG after 27 DOT and was significantly lower than in KBG and TF thereafter. In the control, EL remained consistently low and was similar among the three turfgrasses throughout the study (Fig. 4D).

The EL results from our study agree with Wang and Huang (2004), who reported that EL increased rapidly during the combined stresses of heat and drought in Kentucky bluegrass. Haldimann and Feller (2005) reported that improved thermal stability of thylakoid membranes preserved the functional potential of the photosynthetic apparatus at high temperature and significantly minimized the effect of heat stress in pea (Pisum sativum L.) leaves. Our results suggest that cell membrane stability is higher in HBG than in KBG and TF under high temperature stress.

\section{Dry matter production}


In all treatments and the control, cumulative dry matter production was greater in HBG than in KBG and TF (albeit not significantly in the combination high temperature and drought treatment) and similar between KBG and TF (Fig. 5). Within each species, however, cumulative dry matter production was significantly reduced by high temperature, drought, and the combination of high temperature and drought. High temperature reduced cumulative dry matter production in KBG, $\mathrm{HBG}$, and TF by 88,74 , and $91 \%$ respectively, which was greater than the reduction under drought; drought reduced cumulative dry matter production in $\mathrm{KB}, \mathrm{HBG}$, and TF by 49,48 , and $52 \%$ respectively. Lower cumulative dry matter production in high temperature than in drought was a result, in part, of a dramatic decrease in clippings after the initial $3 \mathrm{~d}$ of treatments compared with the more gradual decline in daily dry matter production under drought as soils dried (data not shown). The combination of high temperature and drought reduced cumulative dry matter production in KBG, $\mathrm{HBG}$, and TF by 95,86 , and $93 \%$ respectively. Within each species, the combination of heat and drought had no additional effect on cumulative dry matter production compared to high heat only.

\section{Evapotranspiration and green leaf area index}

High temperature increased cumulative ET during the study by 57,67 , and $37 \%$ in KBG, HBG, and TF, respectively, compared with the control (Fig. 6A). Interestingly, ET also increased in HBG when exposed to high temperature and drought (i.e., despite reduced irrigation) compared with the control. Presumably, higher vapor pressure deficits contributed to increases in ET in the well-watered, high temperature treatment and to increased ET in HBG or sustained ET in $\mathrm{KBG}$ and $\mathrm{TF}$ in high temperature combined with drought. 
Within the high temperature treatment, cumulative ET in HBG was 13\% greater than in KBG and 22\% greater than in TF (Fig. 6A). Within the drought and high temperature treatment, cumulative ET was $20 \%$ greater in HBG than in TF but was similar between HBG and KBG. In both of the latter treatments, greater ET in HBG may have been caused, in part, by its greater tissue integrity in transpiring leaves than in KBG and TF, as indicated by the lower EL in HBG in those treatments (Figs. 4A and 4C). Greater dry matter production (i.e., clippings) in HBG (Fig. 5) may also have contributed to its greater ET compared with KBG and TF. For example, during the study HBG consistently grew faster and was visibly taller than KBG and TF between mowing. Greater amounts of new growth between mowing indicate a greater surface area of young, actively transpiring leaves in HBG. Green LAI harvested from lysimeters at the end of the study was also higher in HBG than in TF under high temperature (Fig. 6B) indicating a greater surface area of green, transpiring leaves in HBG compared with TF.

Drought alone reduced ET compared with the control, but similar ET among species indicated no differences in drought resistances (Fig. 6A). Similarly, no differences in ET were observed among species in the well-watered, optimal temperatures of the control. Our results contradict those of Suplick-Ploense and Qian (2005), who found that a HBG (Reveille) used less water and exhibited greater drought resistance in the field than a KBG (Bensun's A-34). Our results also differ from Minner and Butler (1985), who found that tall fescue used significantly more water than Kentucky bluegrass by using lysimeters filled with sand to measure ET under field conditions. High variability in water use among individual HBG and cultivars of KBG and TF may partially explain the contrasts between results from those studies and ours; the specific hybrids and cultivars used in their studies were different from those used in ours. Research by others has indicated significant variability in water use among individual cultivars of KBG and 
TF, respectively (Shearman, 1986; Bowman and Macaulay, 1991). Furthermore, considerable variability in relative water content and drought resistance, which suggests variability in water use, was found among $30 \mathrm{HBG}$, and some $\mathrm{HBG}$ exhibited less drought resistance than KBG (Abraham et al., 2004).

Green LAI in HBG was not affected by high temperature compared with the control, but LAI in HBG was reduced (i.e., 56 to 64\%) by drought and by the combination of high temperature and drought (Fig. 6B). High temperature reduced green LAI in KBG compared with the control, and high temperature combined with drought caused further reductions in LAI in KBG compared with high temperature only. Green LAI in KBG was 29, 55, and 61\% lower in high temperature, drought, and combined high temperature and drought treatments, respectively, than in the control. Green LAI in TF was reduced by 38 to $68 \%$ among treatments compared with the control, but differences in green LAI in TF were not significant among stress treatments. Green LAI was similar among all three species in the control.

\section{Canopy and soil-surface temperatures and volumetric soil water content}

In the drought and the combination drought and high temperature treatments, canopy temperatures increased steadily by 4.1 to $4.8^{\circ} \mathrm{C}$ during the study (data not shown). Presumably, decreasing transpiration as the soils dried caused a corresponding decrease in evaporative cooling of leaves and increased drought stress on leaf tissue (Sifers and Beard, 1993). Within each treatment, canopy temperatures were generally similar among species (data not shown).

In the high temperature treatment, mean soil-surface temperatures were consistently cooler in $\mathrm{HBG}$ than in $\mathrm{KBG}$ and $\mathrm{TF}$, by about $1^{\circ} \mathrm{C}$ (data not shown). Cumulative heat (degreehours) at the soil surface was significantly lower in HBG than in KBG and TF under high 
temperature (Fig. 6C), which suggests that long-term heat impacts on meristematic activity may have been reduced in HBG compared with KBG and TF. Under combined high temperature and drought stress, the soil-surface also was consistently cooler in HBG than in KBG and TF on a daily basis (data not shown). Cumulative heat at the soil surface was lower in HBG than in TF, but was statistically similar to KBG. Cooler soil-surface temperatures in HBG exposed to high temperature may have resulted from greater shading of the soil surface, caused by faster growth in HBG between mowing as discussed earlier. Faster growth between mowing may have increased transpiration of the canopy and thus, cooled the air above the soil surface in HBG (Bonos and Murphy, 1999). Under drought alone, there was no difference in soil-surface temperatures among species, which was similar to the control.

Volumetric soil water content inside the lysimeters was similar among species under all treatments and the control (data not shown). At lower depths (i.e., 25 and $45 \mathrm{~cm}$ ) under the combination of high temperature and drought, however, volumetric soil water content was consistently lower in TF and $\mathrm{HBG}$ than in $\mathrm{KBG}$, which indicated that $\mathrm{TF}$ and $\mathrm{HBG}$ were using water from deeper in the profile than KBG.

\section{Aboveground biomass and root biomass density}

In all treatments and the control, total aboveground biomass at the end of the study was greatest in TF, except under high temperature, although more than half was dead (Table 1). In all treatments and the control, dead aboveground biomass was greater in TF than in HBG.

Conversely, in HBG, the living biomass as a percentage of the total was greater than in TF under high temperature, indicating that HBG has a greater resistance to heat than TF. 
High temperature and high temperature combined with drought reduced total root biomass compared with the control and drought treatments (Table 2). These results are similar to other studies where root biomass production was reduced by high temperatures (Howard and Watschke, 1991; Huang et al., 1997; Huang et al, 1998; Xu and Huang 2000a, 2000b; Huang and Liu, 2003). In our drought treatment, total root biomass density was not different among species from the control, indicating drought alone did not reduce total root biomass production of $\mathrm{HBG}$, $\mathrm{KBG}$, or TF. This is contrary to reports by other researchers who observed declines in total root biomass production under drought (Howard and Watschke, 1991; Huang et al., 1997). In our study, 60\% ET replacement (drought treatment) may have stimulated root growth during the early periods of treatment before inhibiting root growth as severity of the drought effects intensified. Thus, forty eight days may be not long enough to show the decline in total root biomass production under drought (60\%ET replacement).

In the lower profile (i.e., 35 to $57.5 \mathrm{~cm}$ ), root mass density was greater in $\mathrm{TF}$ than in HBG and KBG under all treatments (Table 2), which indicates TF may be able to extract soil water from deeper depths than HBG and KBG. A deep extensive root system, which is an important drought-avoidance mechanism, has been observed in TF in other studies (White et al., 1993; Carrow, 1996; Qian et al., 1997, Jiang and Huang, 2001). In a growth chamber study, however, the amount of extractable water by turfgrass roots is limited to the available reservoir inside the lysimeters, whereas in field soils the roots may extract water from lower in the profile. Therefore, TF was probably not able to benefit substantially from its deeper root system in our study.

At shallower depths (i.e., 0 to 15 and 15 to $35 \mathrm{~cm}$ ), root biomass was generally similar among species within each treatment (Table 2). Root biomass was greater in TF than in KBG, 
however, in the middle profile $(15-35 \mathrm{~cm})$ of the control and under the combination of high temperature and drought. Conversely, root biomass was greater in KBG than in TF in the surface layer under the combination of high temperature and drought. Total root biomass at all depths was similar among species within each treatment with the exception of the control, where total root biomass was greater in TF than in KBG.

\section{Conclusions}

In the high temperature treatment, HBG generally exhibited higher visual quality, cumulative Pg, dry matter production, green LAI, and cumulative ET and lower EL and soilsurface temperatures than $\mathrm{KBG}$ and $\mathrm{TF}(\mathrm{P}=0.05)$. High temperature did not affect green LAI in HBG but reduced green LAI in KBG and TF by 29 and 38\%, respectively. Under drought stress, the performance of all species declined and differences among species were negligible. The only exception was in cumulative dry matter production, which was higher in HBG than in KBG and $\mathrm{TF}$ under drought. The combination of high temperature and drought caused reductions in visual quality, cumulative Pg, cumulative dry matter production, and living aboveground biomass among species although mean values were generally greater in HBG late in the study. High temperature and drought combined caused EL and dead aboveground biomass to increase among species although EL was significantly higher in KBG and TF than in HBG late in the study.

In this growth chamber study, $\mathrm{HBG}$ exhibited a higher resistance to heat than $\mathrm{KBG}$ and TF, which suggests that HBG may be better suited for areas where frequent high temperatures may damage other cool-season turfgrasses. Differences in drought resistance were negligible among HBG, KBG, and TF, however, indicating no advantage of this HBG over KBG and TF under dry conditions. Field studies are needed to further investigate the heat and drought 
resistance of HBG, including additional cultivars of HBG, under the actual dynamic and stressful environments where turfgrasses are grown.

Acknowledgements

We extend thanks to the Scotts Co., the Golf Course Superintendents Association of America (GCSAA), the Kansas Turfgrass Foundation, and the Kansas Agricultural Experiment Station for their financial support, Dr. Alan Zuk for his technical assistance, and Drs. George Milliken and Liang Fang for their help with statistical analysis. 


\section{References}

Abraham, E.M., B. Huang, S.A. Bonos, and W.A. Meyer. 2004. Evaluation of drought resistance for Texas bluegrass, Kentucky bluegrass, and their hybrids. Crop Sci. 44:1746-1753.

Basinger, J.M., G.J. Kluitenberg, J.M. Ham, J.M. Frank, P.L. Barnes, and M.B. Kirkham. 2003. Laboratory evaluation of the dual-probe heat-pulse method for measuring soil water content. Vadose Zone J. 2:389-399.

Blum, A., and A. Ebercon. 1981. Cell membrane stability as measurement of drought and heat tolerance in wheat. Crop Sci. 21: 43-47.

Bonos, S., A. and J. A. Murphy. 1999. Growth responses and performance of Kentucky bluegrass under summer stress. Crop Sci. 39:770-774.

Bowman, D.C., and L. Macaulay. 1991. Comparative evapotranspiration rates of tall fescue cultivars. HortScience 26:122-123.

Bremer, D.J. 2003. Evaluation of microlysimeters used in turfgrass evapotranspiraton studies using the dual-probe heat-pulse technique. Agron. J. 95:1625-1632.

Bremer, D.J. and J.M. Ham. 2005. Measurement and partitioning of in situ carbon dioxide fluxes in turfgrasses using a pressurized chamber. Agron. J. 97:627-632 [errata: 98:1375].

Bremer, D.J., K. Su, S.J. Keeley, and J.D. Fry. 2006. Performance in the transition zone of two hybrid bluegrasses compared with Kentucky bluegrass and tall fescue. Applied Turfgrass Sci. [Online]. Available at http://www.plantmanagementnetwork.org/sub/ats/research/2006/hybrid/ (Published 8 Aug. 2006; Verified 23 Oct. 2006).

Campbell, G.S., C. Calissendorff, and J.H. Williams. 1991. Probe for measuring soil-specific heat using the heat-pulse method. Soil Sci. Soc. Am. J. 55:291-293. 
Carrow, R.N. 1996. Drought avoidance characteristics of diverse tall fescue cultivars. Crop Sci. $36: 371-377$.

Dunn, J.H. and K. Diesburg. 2004. Turf management in the transition zone. Hoboken, NJ.

EIFG, Environmental Institute for Golf. 2004. [Online]. Available at http://www.eifg.org/focus/watertg_outcomes.asp (verified 31 May 2006).

Emmons, R.D. 2000. Turfgrass science and management. $3^{\text {rd }}$ ed. Delmar, Albany, NY.

Haldimann P. and U. Feller. 2005. Growth at moderately elevated temperature alters the physiological response of the photosynthetic apparatus to heat stress in pea (Pisum sativum L.) leaves. Plant, Cell and Enviroment. 28:302-317.

Ham, J.M. and R.S. Senock. 1992. On the measurement of soil surface temperature. Soil Sci. Soc. Am. J. 56:370-377.

Hamilton, G.W., and D.V. Waddington. 1999. Infiltration rates on residential lawns in central Pennsylvania. J. Soil Water Conserv. 54:564-568.

Howard, H.F., and T.L. Watschke. 1991. Variable high-temperature tolerance among Kentucky bluegrass cultivars. Agron J. 83:689-693.

Huang, B., R.R. Duncan, and R.N. Carrow. 1997. Drought-resistance mechanisms of seven warm-season turfgrasses under surface soil drying: II. Root aspects. Crop Sci. 37:18631869.

Huang, B., and X. Liu. 2003. Summer root decline: Production and mortality for four cultivars of creeping bentgrass. Crop Sci. 43:258-265.

Huang, B., X. Liu, and J.D. Fry. 1998. Effects of high temperature and poor soil aeration on root growth and viability of creeping bentgrass. Crop Sci. 38:1618-1622.

Jiang, Y., and B. Huang. 2001. Physiological responses to heat stress alone or in combination 
with drought: A comparison between tall fescue and perennial ryegrass. HortScience 36(4):682-686.

Jiang, Y. and B. Huang. 2000. Effects of drought or heat stress alone and in combination on Kentucky bluegrass. Crop Sci. 40:1358-1362.

Marcum, K.B. 1998. Cell membrane thermostability and whole-plant heat tolerance of Kentucky bluegrass. Crop Sci. 38: 1214-1218.

Minner, D.D., and J.D. Butler. 1985. Cool season turfgrass quality as related to evapotranspiration. p. 119. In 1985 Agronomy abstracts, ASA. Madison, WI.

National Assessment Synthesis Team. 2000. Climate change impacts on the United States: The potential consequences of climatic variability and change. US Global Change Research Program. Washington, DC.

Perdomo, P., J.A. Murphy, and G.A. Berkowitz. 1996. Physiology changes associated with performance of Kentucky bluegrass cultivars during summer stress. HortScience 31(7):1182-1186.

Qian, Y.L., J.D. Fry, and W.S. Upham. 1997. Rooting and drought avoidance of warm-season turfgrasses and tall fescue in Kansas. Crop Sci. 37:905-910.

Read, J.C., J.A. Reinert, P.F. Colbaugh, and W.E. Knoop. 1999. Registration of 'Reveille' hybrid bluegrass. Crop Sci. 39:590.

SAS Insititue Inc. 2002-2003. Version 9.1 for Windows. SAS Inst., Cary, NC.

Shearman, R.C. 1986. Kentucky bluegrass cultivar evapotranspiration rates. HortScience 21:455457. 
Sifers, S.I. and J.B. Beard. 1993. Comparative inter- and intra-specific leaf firing resistance to supraoptimal air and soil temps in cool-season turfgrass genotypes. Intl. Turf. Soc. Res. J. 7:621-628.

Song, Y., J.M. Ham, M.B. Kirkham, and G.J. Kluitenberg. 1998. Measuring soil water content under turfgrass using the dual-probe heat-pulse technique. J. Am. Soc. Hortic. Sci. 123:937-941.

Stier, J., E. Koeritz, and J. Frelich. 2005. Fertility and mowing response of heat-tolerant bluegrass and tall fescue in the upper midwest. p.1. In 2005 Agronomy abstracts, ASA. Madison, WI.

Supplick-Ploense, M.R., and Y. Qian. 2005. Evapotranspiration, rooting characteristics, and dehydration avoidance: Comparisons between hybrid bluegrass and Kentucky bluegrass. Int. Turf. Soc. Res. J. 10:891-898.

Tarara, J.M., and J.M. Ham. 1997. Evaluation of dual-probe heat-capacity sensors for measuring soil water content in the laboratory and in the field. Agron. J. 89:535-542.

Teuton, T.C., J.C. Sorochan, S. J. McElroy, C. L. Main, and T. C. Mueller. 2005. Are heat tolerant Kentucky bluegrasses better suited for the transition zone? p.1. In 2005 Agronomy abstracts, ASA.Madison, WI.

Turgeon, A.J. Turfgrass Management. 2002. $6^{\text {th }}$ ed. Prentice Hall, Englewood Cliffs. NJ.

Wang, Z. and B. Huang. 2004. Physiological recovery of Kentucky bluegrass from simultaneous drought and heat stress. Crop Sci. 44:1729-1736.

White, R.H., A.H. Bruneau, and T.J. Cowett. 1993. Drought resistance of diverse tall fescue cultivars. Intl. Turf. Soc. Res. J. 7:607-613.

Xu, Q. and B. Huang. 2000a. Growth and physiological responses of creeping bentgrass to 
changes in air and soil temperatures. Crop Sci. 40:1363-1368.

Xu, Q. and B. Huang. 2000b. Effects of differential air and soil temperature on carbohydrate metabolism in creeping bentgrass. Crop Sci. 40:1368-1374. 


\section{List of figures}

Figure 1. Effects on visual quality rated on a scale of 1 to 9 (1=poorest and 9 =highest) of: high temperature (A), drought (B), high temperature and drought (C), and control (D) in $\mathrm{KBG}, \mathrm{HBG}$, and TF. Symbols along the abscissa of each graph indicate significant differences $(\mathrm{P}=0.05)$ between: HBG and $\mathrm{KBG}(*)$; HBG and TF $(+)$; and $\mathrm{KBG}$ and TF $(\mathrm{X})$; on a given day after treatment initiation (Days of treatment).

Figure 2. Effects on cumulative Pg of: high temperature, drought, high temperature and drought, and control in KBG, HBG, and TF. Means with the same letters were not significantly different $(\mathrm{P}=0.05)$.

Figure 3. Effects on gross photosynthesis $(\mathrm{Pg})$ of high temperature in $\mathrm{KBG}, \mathrm{HBG}$, and TF. Symbols along the abscissa indicate significant differences $(\mathrm{P}=0.05)$ between: HBG and KBG (*); and HBG and TF (+); on a given day after treatment initiation (Days of treatment).

Figure 4. Effects on electrolyte leakage (EL) of: high temperature (A), drought (B), high temperature and drought (C), and control (D) in KBG, HBG, and TF. Symbols along the abscissa of each graph indicate significant differences $(\mathrm{P}=0.05)$ between: $\mathrm{HBG}$ and $\mathrm{KBG}(*)$; and $\mathrm{HBG}$ and TF $(+)$; on a given day after treatment initiation (Days of treatment).

Figure 5. Effects on cumulative dry matter production of: high temperature, drought, high temperature and drought, and control in $\mathrm{KBG}, \mathrm{HBG}$, and TF. Means with the same letters were not significantly different $(\mathrm{P}=0.05)$. 
Figure 6. Effects on cumulative ET (mm) (A), green LAI (B), and degree-hours (C) at the soil surface in: high temperature, drought, high temperature and drought, and control treatments in KBG, HBG, and TF. Means with the same letters in each graph were not significantly different $(\mathrm{P}=0.05)$. 


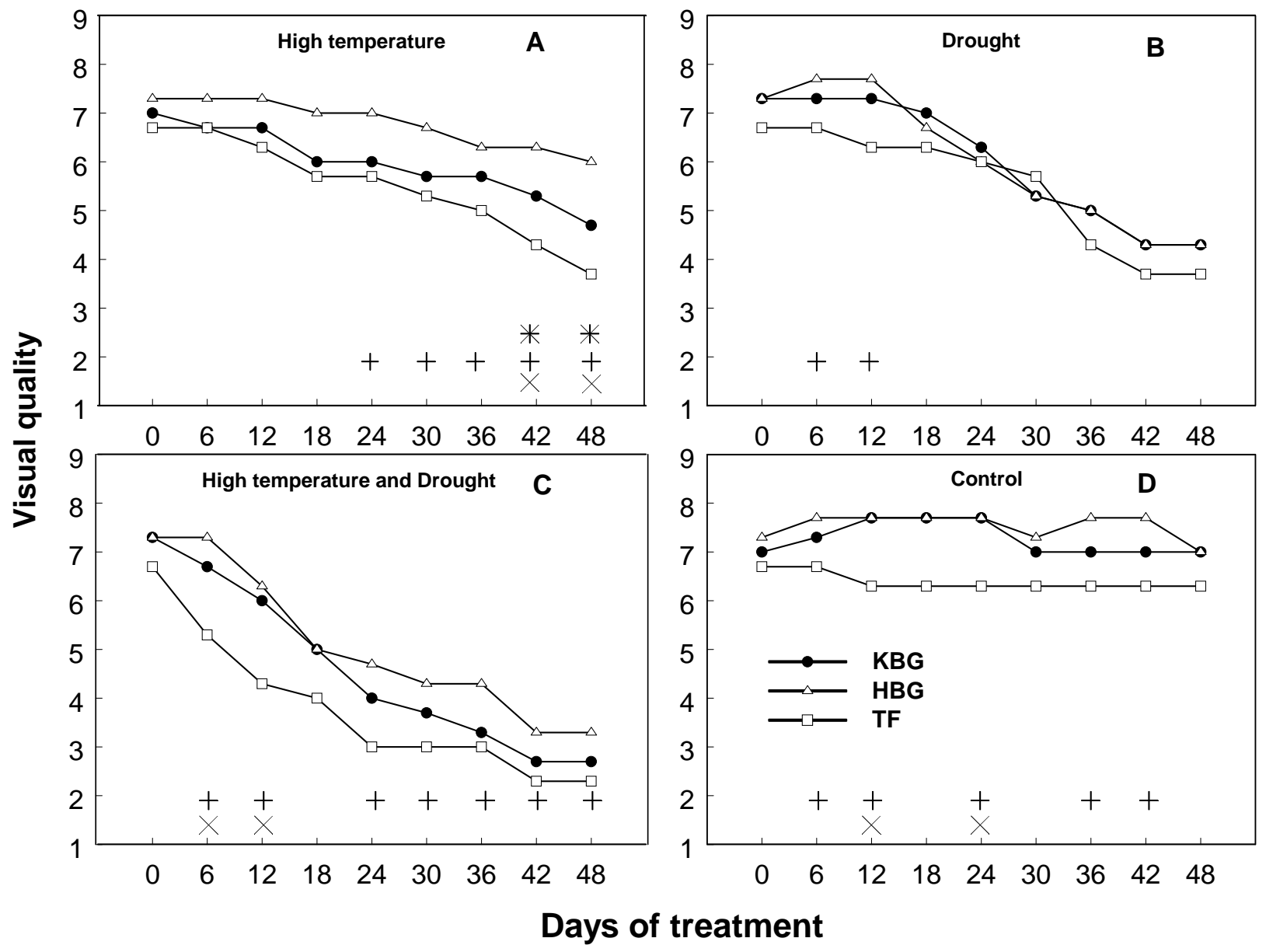

Figure 1. 


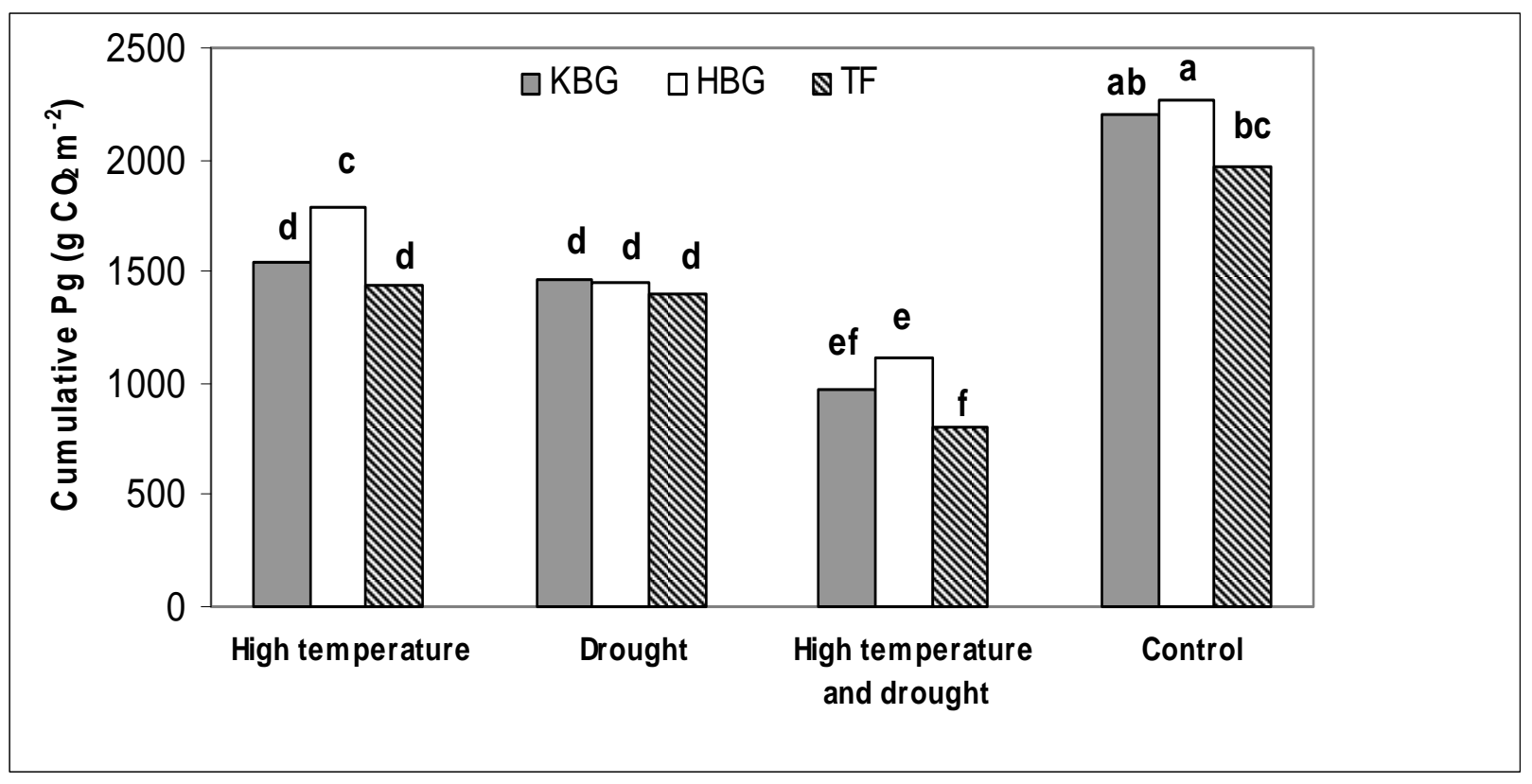

Figure 2 


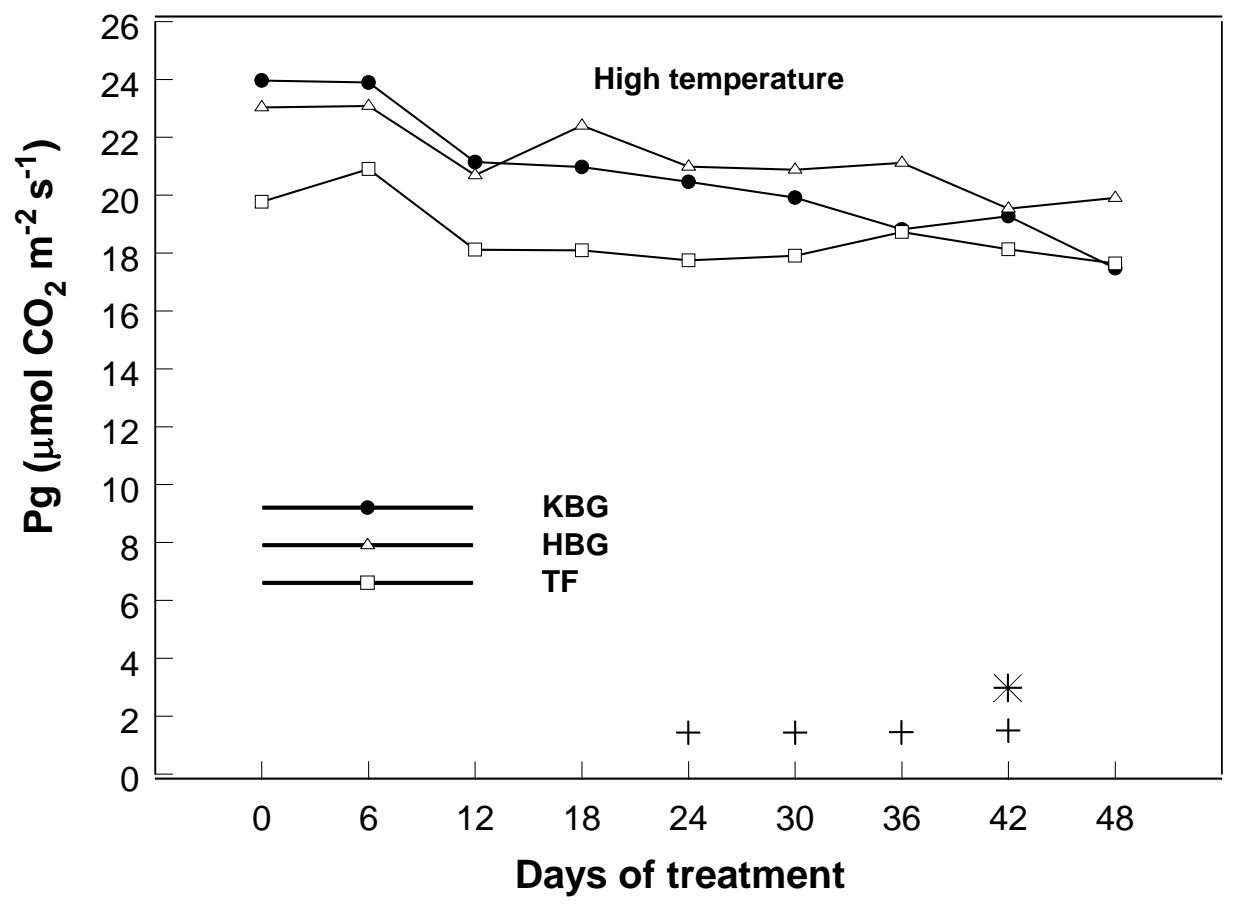

Figure 3 

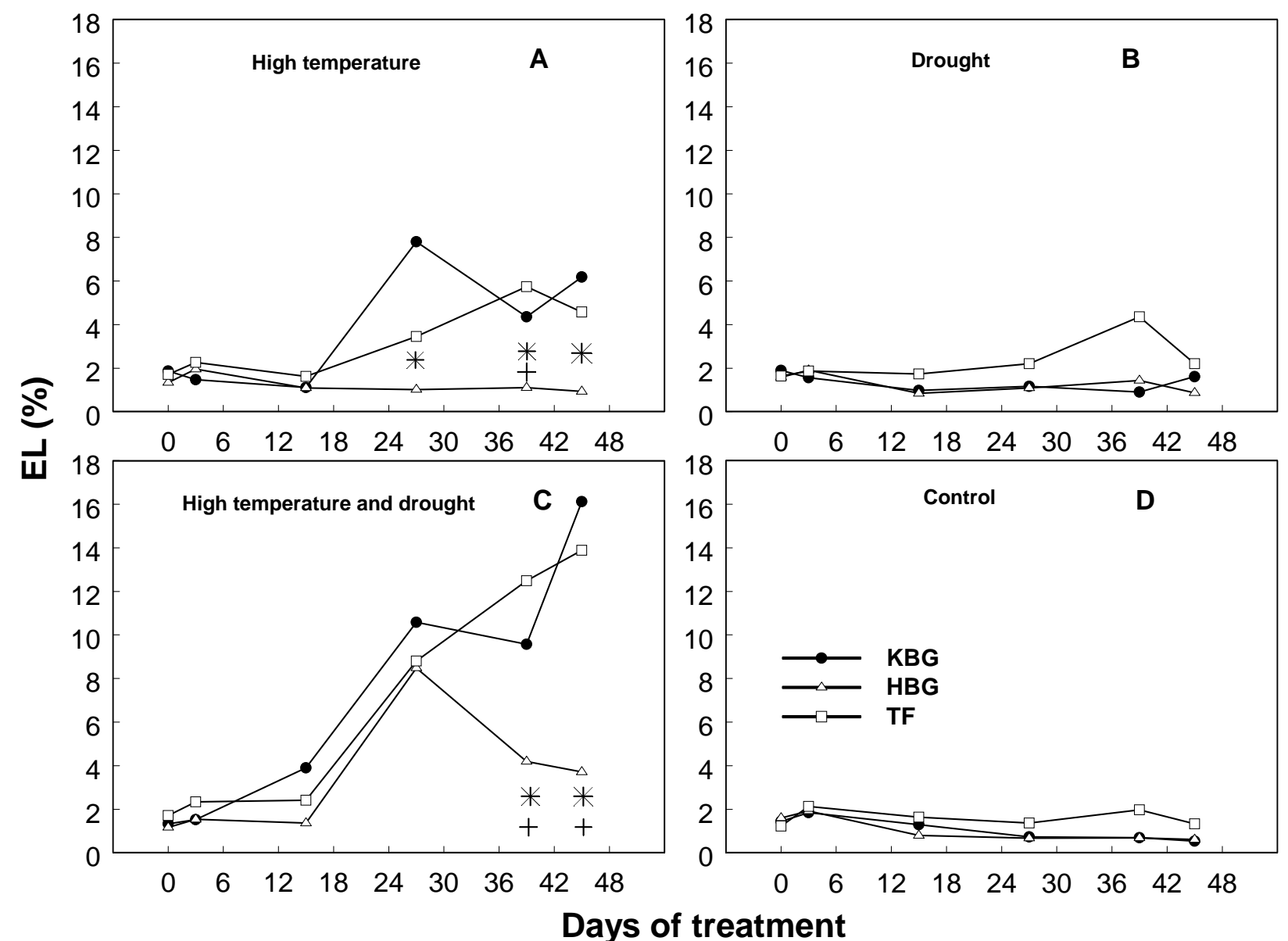

Figure 4 


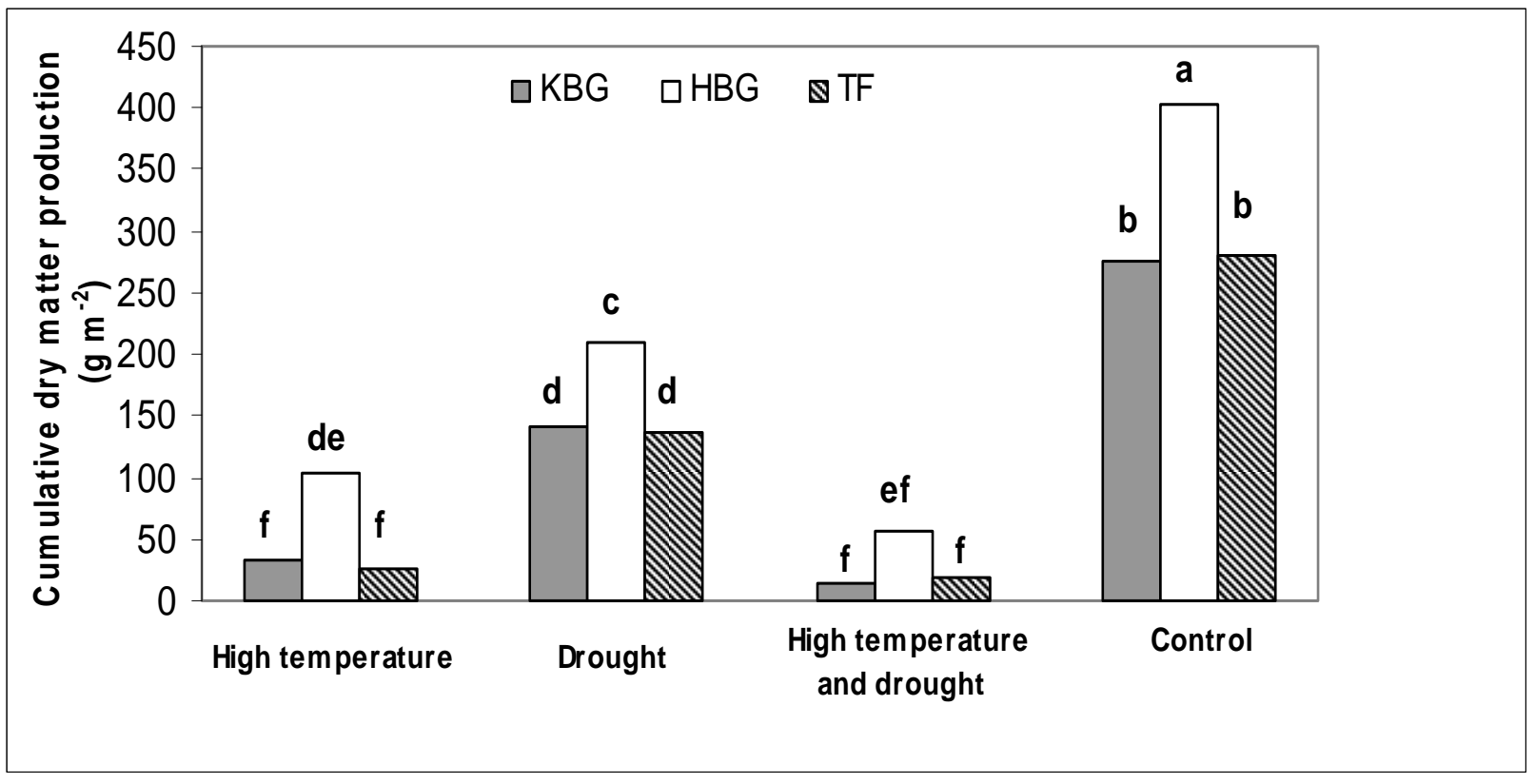

Figure 5 

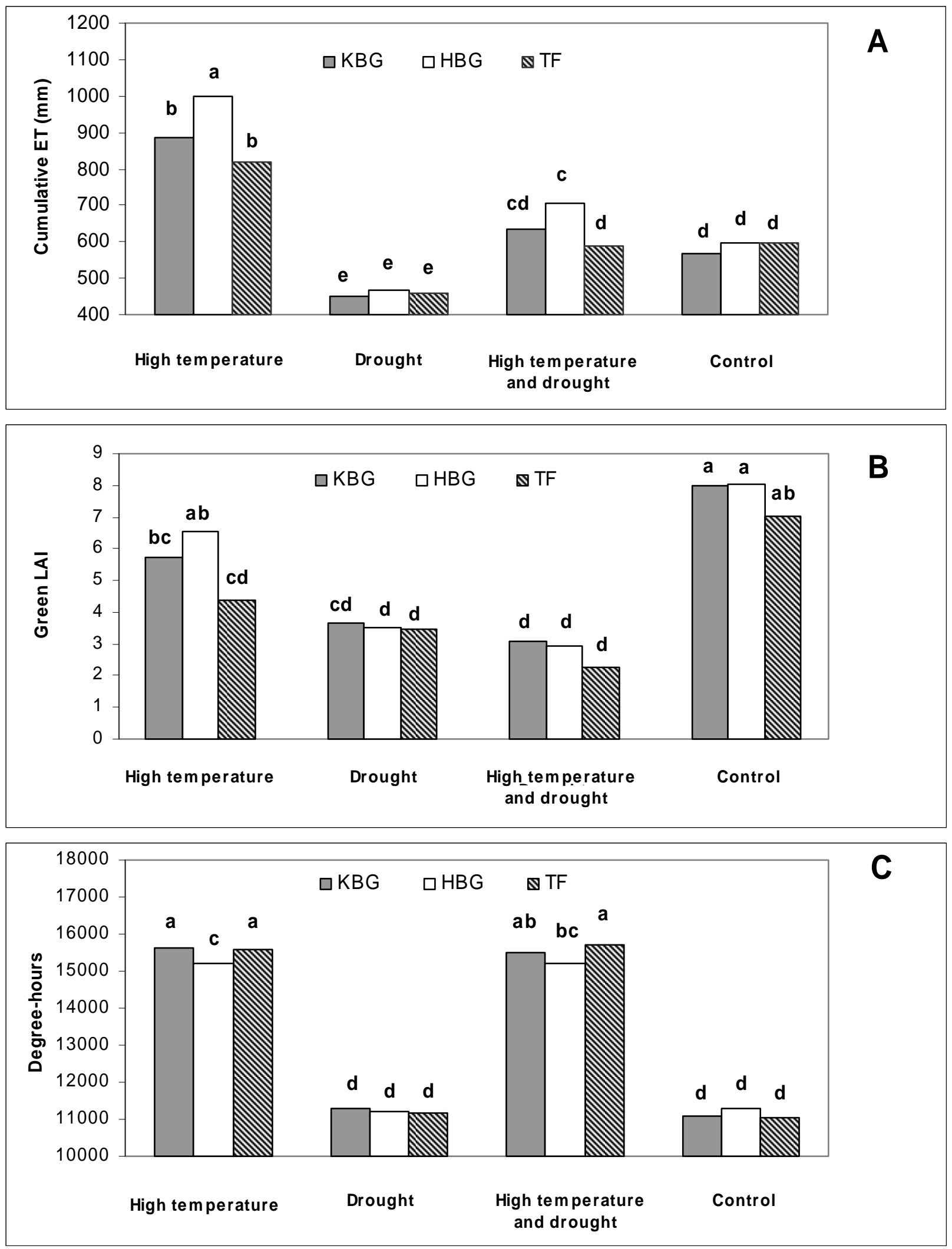

Figure 6 
Table 1. Effects on dry aboveground biomass of high temperature, drought, high temperature and drought, and control in $\mathrm{KBG}, \mathrm{HBG}$, and TF.

\begin{tabular}{|c|c|c|c|c|c|}
\hline \multirow{2}{*}{ Treatments } & \multirow{2}{*}{ Species } & \multicolumn{3}{|c|}{ Aboveground biomass $\left(\mathrm{g} \mathrm{m}^{-2}\right)$} & \multirow{2}{*}{$\begin{array}{l}\text { Percentage } \\
\text { of living } \\
\text { biomass in } \\
\text { total (\%) }\end{array}$} \\
\hline & & Total & Dead & Living & \\
\hline \multirow{3}{*}{ High temperature } & KBG & $1411.8 \mathrm{ef}^{\dagger}$ & 776.4 de & 635.4 bcdef & $45 \mathrm{abcd}$ \\
\hline & $\mathrm{HBG}$ & 1430.6 def & $606.5 \mathrm{de}$ & $824.2 \mathrm{abc}$ & $58 \mathrm{a}$ \\
\hline & $\mathrm{TF}$ & $1706.7 \mathrm{bcd}$ & $1092.6 \mathrm{abc}$ & $614.1 \mathrm{cdef}$ & 36 cde \\
\hline \multirow{3}{*}{ Drought } & KBG & 1596.4 cde & 869.5 bcde & $726.9 \mathrm{abcd}$ & $46 \mathrm{abcd}$ \\
\hline & $\mathrm{HBG}$ & 1338.7 ef & $687.2 \mathrm{de}$ & 651.5 bcde & $49 \mathrm{abc}$ \\
\hline & $\mathrm{TF}$ & $1932.6 \mathrm{ab}$ & $1153.6 \mathrm{ab}$ & $779.0 \mathrm{abc}$ & 40 bcde \\
\hline \multirow{3}{*}{$\begin{array}{l}\text { High temperature } \\
\text { and drought }\end{array}$} & KBG & $1266.4 \mathrm{f}$ & $903.1 \mathrm{abcd}$ & $363.3 \mathrm{f}$ & $29 \mathrm{de}$ \\
\hline & $\mathrm{HBG}$ & $1179.7 \mathrm{f}$ & $718.0 \mathrm{de}$ & 461.7 def & 39 bcde \\
\hline & $\mathrm{TF}$ & $1581.3 \mathrm{cde}$ & $1205.0 \mathrm{a}$ & $376.3 \mathrm{ef}$ & $24 \mathrm{e}$ \\
\hline \multirow{3}{*}{ Control } & $\mathrm{KBG}$ & $1717.6 \mathrm{bc}$ & 802.2 cde & $915.5 \mathrm{ab}$ & $53 \mathrm{ab}$ \\
\hline & $\mathrm{HBG}$ & $1444.8 \mathrm{cdef}$ & $571.4 \mathrm{e}$ & $873.4 \mathrm{abc}$ & $60 \mathrm{a}$ \\
\hline & $\mathrm{TF}$ & $2151.1 \mathrm{a}$ & $1207.4 \mathrm{a}$ & $943.6 \mathrm{a}$ & 44 abcd \\
\hline
\end{tabular}

${ }^{\dagger}$ Means followed by the same letter within a column were not significantly different $(\mathrm{P}=0.05)$. 
Table 2. Effects on root mass density of high temperature, drought, high temperature and drought, and control in $\mathrm{KBG}, \mathrm{HBG}$, and TF.

\begin{tabular}{|c|c|c|c|c|c|}
\hline \multirow{2}{*}{ Treatments } & \multirow{2}{*}{ Species } & \multicolumn{4}{|c|}{ Root mass density } \\
\hline & & Total & 0 to $15 \mathrm{~cm}$ & 15 to $35 \mathrm{~cm}$ & 35 to $57.5 \mathrm{~cm}$ \\
\hline \multirow{4}{*}{ High temperature } & \multicolumn{5}{|c|}{ 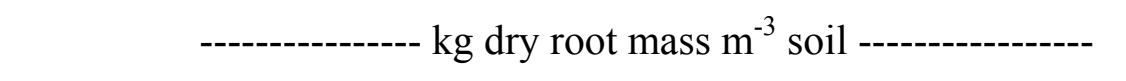 } \\
\hline & $K B G$ & $2.01 d^{\dagger}$ & $6.30 \mathrm{~cd}$ & $0.59 e$ & $0.40 \mathrm{de}$ \\
\hline & HBG & $2.16 \mathrm{~d}$ & $6.58 \mathrm{~cd}$ & $0.84 \mathrm{de}$ & $0.38 \mathrm{de}$ \\
\hline & $\mathrm{TF}$ & $2.23 \mathrm{~d}$ & $5.71 \mathrm{~cd}$ & 0.95 cde & $1.06 \mathrm{bc}$ \\
\hline \multirow{3}{*}{ Drought } & $\mathrm{KBG}$ & $3.01 \mathrm{~b}$ & $8.82 \mathrm{a}$ & $1.13 \mathrm{bcd}$ & $0.80 \mathrm{bcde}$ \\
\hline & $\mathrm{HBG}$ & $3.11 \mathrm{ab}$ & $8.72 \mathrm{a}$ & $1.37 \mathrm{ab}$ & $0.92 \mathrm{bcd}$ \\
\hline & $\mathrm{TF}$ & $3.31 \mathrm{ab}$ & $8.15 \mathrm{ab}$ & $1.51 \mathrm{ab}$ & $1.69 \mathrm{a}$ \\
\hline \multirow{3}{*}{$\begin{array}{l}\text { High temperature } \\
\text { and drought }\end{array}$} & $\mathrm{KBG}$ & $2.19 \mathrm{~d}$ & $7.14 \mathrm{bc}$ & $0.55 \mathrm{e}$ & $0.34 \mathrm{e}$ \\
\hline & $\mathrm{HBG}$ & $2.17 \mathrm{~d}$ & $6.37 \mathrm{~cd}$ & 0.89 cde & 0.52 cde \\
\hline & $\mathrm{TF}$ & $2.31 \mathrm{~cd}$ & $5.41 \mathrm{~d}$ & $1.14 \mathrm{bcd}$ & $1.29 \mathrm{ab}$ \\
\hline \multirow{3}{*}{ Control } & KBG & $2.90 \mathrm{bc}$ & $9.01 \mathrm{a}$ & 0.92 cde & 0.59 cde \\
\hline & $\mathrm{HBG}$ & $3.10 \mathrm{ab}$ & $9.07 \mathrm{a}$ & $1.30 \mathrm{abc}$ & 0.73 cde \\
\hline & $\mathrm{TF}$ & $3.73 \mathrm{a}$ & $9.49 \mathrm{a}$ & $1.60 \mathrm{a}$ & $1.78 \mathrm{a}$ \\
\hline
\end{tabular}

$\uparrow$ Means followed by the same letter within a column were not significantly different $(\mathrm{P}=0.05)$. 